Research Article

\title{
The Evolutionary Game Analysis of Public Opinion Supervision of Engineering Quality in the Network Citizen Journalism Environment
}

\author{
Yaohong Yang $\mathbb{D}$, Yi Zeng $\mathbb{D}$, Jing Dai $\mathbb{D}$, and Ying Liu $\mathbb{C}$ \\ School of Water Conservancy, North China University of Water Resources and Electric Power, Zhengzhou, Henan 450046, China \\ Correspondence should be addressed to Yaohong Yang; yangyaohong@ncwu.edu.cn
}

Received 8 September 2021; Revised 6 October 2021; Accepted 1 November 2021; Published 27 November 2021

Academic Editor: Sang-Bing Tsai

Copyright ( 2021 Yaohong Yang et al. This is an open access article distributed under the Creative Commons Attribution License, which permits unrestricted use, distribution, and reproduction in any medium, provided the original work is properly cited.

\begin{abstract}
With the rapid development of mobile networks and citizen journalism, public opinion supervision has become an essential social supervision on engineering quality. They consider the dynamic characteristics of the spread process of public opinion and the game process of social supervision on engineering quality. The tripartite evolutionary game model of the government, contractors, and the public was constructed by coupling the Susceptible-Exposed-Infected-Removed (SEIR) model of public opinion spread and the evolutionary game model. Then, the influence laws of public opinion spread on the tripartite evolutionary game were analyzed and discussed through numerical simulation analysis. The results show that the public with more significant influence or authority is more able to restrain the quality behavior of government and contractors; increasing the probability of transforming ignorant into latent, the probability of converting latent into the communicator and topic derivation rate or reducing the direct immunization selfhealing can improve the effectiveness of public opinion supervision; the true online public opinion can effectively restrain the quality behavior of contractors and urge the government to supervise actively. The research conclusions can provide a reference for improving the social supervision mechanism of engineering quality in the era of network citizen journalism.
\end{abstract}

\section{Introduction}

Project quality is related to national economic development and social stability and is an important cornerstone for achieving high-quality project development. With the continuous improvement of project quality requirements, the public is paying more and more attention to project quality supervision. At the same time, the number and scale of construction projects continue to expand, engineering quality accidents also from time to time [1]. Therefore, we must pay attention to the participation of all parties in society and improve the social supervision mechanism of project quality [2]. There have been a lot of researches on the quality and safety social supervision mechanism of chemical production and food industries $[3,4]$, and social supervision can restrain the environmental behavior of enterprises at the same time $[5,6]$. Relevant scholars have studied social supervision issues during the construction and operation period of environmental public-private partnerships (PPP) projects [7], major projects, and social supervision issues for investment decisions in large-scale public projects $[8,9]$.

Media supervision is one of the important forms of social supervision. Peng [10] discussed the influence of the media "opinion leader" model on consumers' buying behavior. Cao et al. [11] analyzed the effect of the influence and authenticity of new media reports on the choice of evolutionary game strategies between government regulatory agencies and food companies. Sun and Zhu [12] discussed the impact of the accuracy of media reports on the three-party game strategy of government regulatory agencies, food manufacturers, and consumers on food regulation. With the rapid development of mobile networks and self-media, the public regards self-media as the main vehicle for expressing public opinion. Fei and Pan [13] analyzed the direct and indirect effects of the influence and authenticity of self-media exposure of food safety issues on relevant subjects of food safety supervision. Cao and $\mathrm{Wu}$ 
[14] studied the impact of public participation rate and online public opinion on social organizations, government departments, and third-party evaluation agencies in the "Internet +" environment. These studies have generalized the influence of the spread of online public opinion into a parameter to express. The dissemination of online public opinion is a dynamic and complex process, including multiple subjects and multiple influencing factors, and has its own regularity. In 1964, Goffman and Newill [15] applied the infectious disease susceptible infected recovered (SIR) model to the field of information dissemination for the first time. Scholars at home and abroad study online public opinion dissemination based on SIS [16], SEIR [17], SCIR [18], and other information dissemination models. Zhang et al. [19] proposed a rumor dissemination model that considers the superdissemination mechanism and studied the influence of superdissemination on rumors. Yu et al. [20] applied a new I2SR propagation model in a heterogeneous network and proposed an eventtriggered impulse control strategy that depends on the number of communicators to control the spread of rumors. This kind of network public opinion dissemination model is mostly used to study the dissemination of network rumors. Internet public opinion has not only negative effects but also positive effects. For example, improving the SIR model can effectively improve the efficiency of information dissemination in reading promotion of university libraries [21]. And it can also maximize the effectiveness of advertising information dissemination in social networks [22]. The public can also supervise the quality of the project through online public opinion, effectively restraining the quality behavior of the government and enterprises.

Based on the network self-media environment, this article discusses the conditions under which the main body strategy of the tripartite game tends to be stable. Discuss the rule of influence on the evolutionary trajectory of the tripartite subject after the changes of the public node degree, the conversion probability between nodes, and the authenticity of public opinion supervision. Finally, suggestions to improve the effectiveness of online public opinion supervision are put forward. The main contributions of this paper are as follows: (1) coupling the network public opinion dissemination model with the evolutionary game model; (2) based on the simulation analysis, the influence law of the main parameters in the model is summarized, and suggestions are put forward to improve the effectiveness of network public opinion supervision.

The organizational structure of this paper is as follows. Section 2 gives the SEIR model and the evolutionary game model. Section 3 analyzes the analysis of evolutionary stability strategy. Section 4 gives numerical simulation. Finally, a summary of some articles is given Section 5 .

\section{SEIR Model and Evolutionary Game Model}

2.1. SEIR Model. Chen et al. [23] divide $\mathrm{N}$ individuals in online social network systems into four categories. They are as follows: (1) ignorant (S), netizen who have not obtained public opinion information; (2) the lurker $(E)$, the netizen who has been exposed to public opinion but is still hesitating; (3) communicator (I), Internet users who spread relevant public opinion information; (4) immunized persons (R), netizen who receive public opinion but do not spread it or lose interest after spreading it. The transition process between the four types of node states is shown in Figure 1.

The figure shows the probability $\rho$ of the ignorant transforming into a latent; some lurkers interested in the public opinion information can be transformed into probability $\beta$ or directly into immune ones with probability $\varepsilon$. The communicator becomes an immune person with probability $\gamma$ due to external factors or his own degree of interest. When a public opinion event derives a new topic, the immunized person will rechoose to disseminate public opinion information with probability $\tau$. The establishment of a public opinion dissemination model is

$$
\left\{\begin{array}{l}
\frac{\mathrm{d} S}{\mathrm{~d} t}=-\frac{[\rho k \theta(t) S(t)]}{N} \\
\frac{\mathrm{d} E}{\mathrm{~d} t}=\frac{[\rho k \theta(t) S(t)]}{N}-\frac{[\beta k \theta(t) E(t)]}{N}-\varepsilon E(t), \\
\frac{\mathrm{d} I}{\mathrm{~d} t}=\frac{[\beta k \theta(t) E(t)]}{N}-\gamma I(t)+\tau R(t), \\
\frac{\mathrm{d} R}{\mathrm{~d} t}=\gamma I(t)+\varepsilon E(t)-\tau R(t), \\
S(t)+E(t)+I(t)+R(t)=N .
\end{array}\right.
$$

$k$ is the node degree of initial communicator $\theta(t)$ is the probability that any edge of the scale-free network is connected to the communicator. The calculation formula is

$$
\theta(t)=\frac{\sum_{k} k p(k) I(t)}{\langle k\rangle},
$$

where $p(k)$ is the degree distribution function and $k$ is the network node centrality.

\subsection{Evolutionary Game Model}

Hypothesis 1: the government's strategy is active supervision and nonactive supervision. The probability that the government chooses active supervision is $x$. The probability of inactive supervision is $1-x$. The contractor's strategic space is normal quality behavior and quality deceptive behavior, and the contractor's probability of choosing normal quality behavior is $y$. The probability of choosing quality deception is $1-y$. The public's strategy is public opinion supervision and nonpublic opinion supervision. The probability that the public chooses public opinion supervision is $z$. The probability of not being supervised by public opinion is $1-z$.

Hypothesis 2: the government needs to pay for active supervision in $C 1$. As long as the government actively supervises, it will be able to detect the quality deception of contractors first. The cost of inactive supervision is 


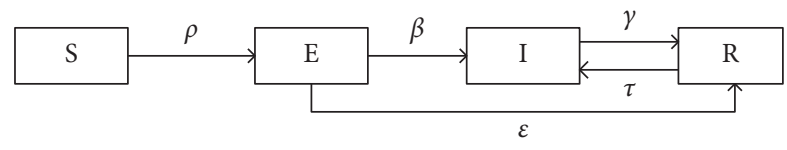

Figure 1: Node state transition diagram.

C2. When the government neglects its duty and chooses to monitor public opinion, the government must conduct inspections. Cost is $C 3$. And it must be able to verify the contractor's quality behavior. The government finds that the quality of the contractor's deception will punish the contractor as $P b$.

Hypothesis 3: the contractor's choice of quality deception will gain additional benefits as $P 1$. The government will impose penalties on the quality of deceptive behaviors of contractors and require the contractors to repair or rework. The cost is P2. Public opinion supervision by the public will incur a certain cost $\alpha$, including time and energy costs. The public affected by the project suffered losses due to the quality deception of the contractor is $A$.

Hypothesis 4: the information exposed by public opinion supervision is not necessarily true, and there is distortion. When the government actively supervises, it will respond to public opinion quickly and effectively. Therefore, the government actively supervises, and the government credibility rises $M$. Contractor faces losses $F$. Public gains $G$. When the government does not actively supervise $N$, the government's credibility decreases.

Hypothesis 5: under the active supervision of the government, the numbers of ignorant, latent, communicator, and immune are $S 1, E 2, I 1$, and $R 1$, respectively. Probability of an ignorant person turning into a lurking person is $\beta 1$. Probability of conversion from latent person to communicator is $\beta 1$. Direct immunization rate is $\varepsilon 1$. Probability of self-healing by communicator is $\gamma 1$. Topic derivation rate is $\tau 1$. $p 1<p 2, \beta 1<\beta 2, \varepsilon 1,<\varepsilon 2, \gamma 1>\gamma 2, \tau 1<\tau 2$. The moment of initial dissemination of online public opinion: $S 0=S 1=S 2, E 0=E 1=E 2, I 0=I 1=12, R 0=R 1=R 2$.

Hypothesis 6: the influence of the spread of online public opinion on the benefits of the three parties in the evolutionary game lies in the scope of the spread of online public opinion. Therefore, the benefits for the three parties are determined by the maximum value of the communicator and the immune. In disseminating public opinion information by the initial communicator, change of government credibility unit for each additional communicator is $m 1$. Contractor unit opportunity cost is $f 1$. Public unit income is $g 1$. The amount of change in the government credibility unit for each additional immunized person is $m 2$. Contractor unit opportunity cost is $f 2$. Public unit income is $g 2, m 1>m 2, f 1>f 2, g 1>g 2$.

Based on the above assumptions, the profit matrix of the three parties in the evolutionary game is established, as shown in Table 1.

$$
\begin{aligned}
M & =\left(\max I_{1}-I_{0}\right) m_{1}+\left(\max R_{1}-R_{0}\right) m_{2}, \\
N & =\left(\max I_{2}-I_{0}\right) m_{1}+\left(\max R_{2}-R_{0}\right) m_{2}, \\
F & =\left(\max I_{1}-I_{0}\right) f_{1}+\left(\max R_{1}-R_{0}\right) f_{2}, \\
H & =\left(\max I_{2}-I_{0}\right) f_{1}+\left(\max R_{2}-R_{0}\right) f_{2}, \\
G & =\left(\max I_{1}-I_{0}\right) g_{1}+\left(\max R_{1}-R_{0}\right) g_{2}, \\
S & =\left(\max I_{2}-I_{0}\right) g_{1}+\left(\max R_{2}-R_{0}\right) g_{2} .
\end{aligned}
$$

\section{Evolutionary Stability Strategy Analysis}

3.1. Copy Dynamic Equation. The expected benefits of the government choosing active supervision are

$$
\begin{aligned}
U_{11}= & y z\left[-C_{1}+(1-a) M\right]+y(1-z)\left(-C_{1}\right) \\
& +(1-y) z\left(-C_{1}+a M+P_{b}\right) \\
& +(1-y)(1-z)\left(-C_{1}+P_{b}\right) .
\end{aligned}
$$

The expected benefits of the government choosing not to regulate actively are

$$
\begin{aligned}
U_{12}= & y z\left[-C_{2}-C_{3}-(1-a) N\right]+y(1-z)\left(-C_{2}\right) \\
& +(1-y) z\left(-C_{2}-C_{3}-a N+P_{b}\right)+(1-y)(1-z)\left(-C_{2}\right) .
\end{aligned}
$$

The average government revenue is

$$
\overline{U_{1}}=x U_{11}+(1-x) U_{12} .
$$

It can be obtained that the dynamic equation of replication that the government chooses to actively supervise is

$$
\begin{aligned}
F(x)= & x(1-x)\left\{-y P_{b}+z\left[a(N+M)-P_{b}+C_{3}\right]\right. \\
& \left.+y z\left[(1-2 a)(M+N)+P_{b}\right]+P_{b}-C_{1}+C_{2}\right\} .
\end{aligned}
$$

The expected benefits of the contractor's choice of normal quality behavior and quality deceptive behavior are

$$
\begin{aligned}
U_{21}= & -x z(1-a) F-(1-x) z(1-a) H, \\
U_{22}= & x z\left(P_{1}-a F-P_{b}-P_{2}\right)+x(1-z)\left(P_{1}-P_{b}-P_{2}\right) \\
& +(1-x) z\left(P_{1}-a H-P_{b}-P_{2}\right)+(1-x)(1-z) P_{1} .
\end{aligned}
$$

The average contractor's revenue is

$$
\overline{U_{2}}=y U_{21}+(1-y) U_{22} .
$$

The dynamic equation of replication when the contractor chooses the normal quality behavior is

$$
\begin{aligned}
F(y)= & y(1-y)\left\{x\left(P_{b}+P_{2}\right)+z\left[(2 a-1) H+P_{b}+P_{2}\right]\right. \\
& \left.+x z\left[(2 a-1)(F-H)-P_{b}-P_{2}\right]-P_{1}\right\} .
\end{aligned}
$$

The expected benefits of public opinion supervision and nonpublic opinion supervision are as follows: 
TABle 1: The payout matrix of the main body of the game.

\begin{tabular}{lcccc}
\hline & \multicolumn{2}{c}{$\begin{array}{c}\text { Active government } \\
\text { supervision }\end{array}$} & \multicolumn{2}{c}{$\begin{array}{c}\text { The government does not } \\
\text { actively supervise }\end{array}$} \\
Contractor & $\begin{array}{c}\text { Public opinion } \\
\text { supervision }\end{array}$ & $\begin{array}{c}\text { Public opinion } \\
\text { supervision }\end{array}$ & $\begin{array}{c}\text { Public opinion } \\
\text { supervision }\end{array}$ & $\begin{array}{c}\text { Public opinion } \\
\text { supervision }\end{array}$ \\
\hline \multirow{2}{*}{ Normal quality behavior } & $-C_{1}+(1-a) M$ & $-C_{1}$ & $-C_{2}-C_{3}-(1-a) N$ & $-C_{2}$ \\
& $-(1-a) F$ & 0 & $-(1-a) H$ & 0 \\
Quality deception & $-\alpha+(1-a) G$ & 0 & $-\alpha+(1-a) S$ & $-C_{2}$ \\
& $-C_{1}+a M+P_{b}$ & $-C_{1}+P_{b}$ & $-C_{2}-C_{3}-a N+P_{b}$ & $P_{1}$ \\
& $P_{1}-a F-P_{b}-P_{2}$ & $P_{1}-P_{b}-P_{2}$ & $P_{1}-a H-P_{b}-P_{2}$ & $-A+a S$ \\
\hline
\end{tabular}

$$
\begin{aligned}
U_{31}= & x y[-\alpha+(1-a) G]+x(1-y)(-\alpha+a G) \\
& +(1-x) y[-\alpha+(1-a) S]+(1-x)(1-y)(-\alpha+a S), \\
U_{32}= & (1-x)(1-y)(-A) .
\end{aligned}
$$

$$
\begin{aligned}
F(z)= & z(1-z)\{x[a(G-S)-A]+y[(1-2 a) S-A] \\
& +x y[(1-2 a)(G-S)+A]-\alpha+a S+A\}
\end{aligned}
$$

The average income of the public is

$$
\overline{U_{3}}=z U_{31}+(1-z) U_{32} \text {. }
$$

The dynamic equation for copying public opinion supervision by the public is
3.2. Analysis of Evolutionary Stable Points. $F(x)=0, F(y)=0, F(z)=0,(0,0,0),(0,0,1),(0,1,0),(0$, $1,1),(1,0,0),(1,0,1),(1,1,0)$, and $(1,1,1) 8$ special equilibrium points and a mixed strategy equilibrium solution $\left(x^{*}, y^{*}, z^{*}\right)$.

$$
\left\{\begin{array}{l}
x^{*}=\frac{-y[(1-2 a) S-A]+\alpha-a S-A}{a(G-S)-A+y[(1-2 a)(G-S)+A]}, \\
y^{*}=\frac{-z\left[a(N+M)-P_{b}+C_{3}\right]-P_{b}+C_{1}-C_{2}}{-P_{b}+z\left[(1-2 a)(M+N)+P_{b}\right]}, \\
z^{*}=\frac{-x\left(P_{b}+P_{2}\right)+P_{1}}{(2 a-1) H+P_{b}+P_{2}+x\left[(2 a-1)(F-H)-P_{b}-P_{2}\right]} .
\end{array}\right.
$$

The evolutionary stable equilibrium of the multi-group evolutionary game must be a strict Nash equilibrium. The Nash equilibrium of mixed strategy cannot resist multiple cumulative small disturbances and eventually evolves to a pure strategy. Therefore, the stability of the equilibrium point of the mixed strategy is not discussed [24]. According to the method proposed by Friedman, the stability of the equilibrium point of the game process is judged by analyzing the local stability of the Jacobi matrix of the differential equation system [25]. For a linear time-invariant system, the equilibrium point when all eigenvalues in the matrix are nonpositive values is the system's (ESS). The Jacobi matrix of the three-party game between the government, the contractor, and the public to replicate the dynamic equations is

$$
\mathbf{T}=\left(\begin{array}{ccc}
(1-2 x)\left\{-y P_{b}+z[a(N+M)\right. & x(1-x)\left\{-P_{b}+z\left[(1-2 a)(M+N)+P_{b}\right]\right\} & x(1-x)\left\{a(N+M)-P_{b}+C_{3}\right. \\
\left.-P_{b}+C_{3}\right]+y z[(1-2 a)(M+N) & & \left.+y\left[(1-2 a)(M+N)+P_{b}\right]\right\} \\
\left.\left.+P_{b}\right]+P_{b}-C_{1}+C_{2}\right\} & (1-2 y)\left\{x\left(P_{b}+P_{2}\right)+z\left[(2 t-1) H+P_{b}+P_{2}\right]\right. & y(1-y)\left\{(2 t-1) H+P_{b}+P_{2}\right. \\
y(1-y)\left\{P_{b}+P_{2}+z[(2 t-1)\right. & \left.+x z\left[(2 t-1)(F-H)-P_{b}-P_{2}\right]-P_{1}\right\} & \left.+x\left[(2 t-1)(F-H)-P_{b}-P_{2}\right]\right\} \\
\left.\left.(F-H)-P_{b}-P_{2}\right]\right\} & z(1-z)\{(1-2 a) S-A+x[(1-2 a)(G-S)+A]\} & (1-2 z)\{x[a(G-S)-A]+y[(1-2 a) S-A]+x y[(1-2 a)(G-S)+A]-\alpha+a S+A\}
\end{array}\right) .
$$

Substituting the 8 partial equilibrium points into the above Jacobi matrix, the eigenvalues corresponding to the 8 partial equilibrium points are solved, as shown in Table 2.
It shows that contractors will not tend to choose normal quality behaviors overtime under the circumstances that the government does not actively supervise and the public does 
TABLE 2: Eigenvalues of equilibrium points.

\begin{tabular}{lccc}
\hline Equilibrium point & $\lambda_{1}$ & $\lambda_{2}$ & $\lambda_{3}$ \\
\hline$(0,0,0)$ & $-C_{1}+C_{2}+P_{b}$ & $-P_{1}$ & $-\alpha+a S+A$ \\
$(0,0,1)$ & $-C_{1}+C_{2}+C_{3}+a(N+M)$ & $-P_{1}+P_{b}+P_{2}+(2 a-1) H$ & $-(-\alpha+a S+A)$ \\
$(0,1,0)$ & $-C_{1}+C_{2}$ & $P_{1}$ & $-\alpha+(1-a) S$ \\
$(0,1,1)$ & $-C_{1}+C_{2}+C_{3}+(1-a)(N+M)$ & $-\left[-P_{1}+P_{b}+P_{2}+(2 a-1) H\right]$ & $-[-\alpha+(1-a) S]$ \\
$(1,0,0)$ & $-\left(-C_{1}+C_{2}+P_{b}\right)$ & $-P_{1}+P_{b}+P_{2}$ & $-\alpha+a G$ \\
$(1,0.1)$ & $-\left[-C_{1}+C_{2}+C_{3}+a(N+M)\right]$ & $-P_{1}+P_{b}+P_{2}+(2 a-1) F$ & $-(-\alpha+a G)$ \\
\hline
\end{tabular}

not supervise public opinion. The cost of active government supervision is greater than the cost of inactive supervision.

$C 1>C 2, C 1--C 2>0$. This means that when the public does not supervise public opinion, relying only on the active supervision of the government will not make contractors tend to choose normal quality behaviors.

$-C 1+C 2+C 3+(1-a) \quad(N+M)<0, \quad-P 1+P b+P 2+$ $(2 a-1) H>0,-a+(1-a) S>0$. That is to say, the benefits of active government supervision are less than those of inactive supervision, and when the government does not actively supervise, the benefits of contractors who choose normal quality behaviors are greater than the benefits of quality cheating behaviors. The benefits of public opinion monitoring by the public are greater than the costs. The mainstay strategy tends to $(0,1,1)$.

$-C 1+C 2+C 3+(1-a)(N+M)>0, \quad-P 1+P b+P 2$ $+(2 a-1) F>0,-a+(1-a) G>0$. $(1,1,1)$ is a stable threeparty strategy. This is because the benefits of active government supervision are greater than the benefits of nonactive supervision and under active government supervision. The benefits of contractors choosing normal quality behaviors are greater than those of quality deceptive behaviors, and the benefits of public opinion monitoring are greater than the costs.

Because the supervision of public opinion on the public network is a stable strategy that influences the government, contractors, and the public through changes in the number of communicators and through public opinion dissemination, it is not possible to simply analyze the characteristics of the eight equilibrium points to find out the influence of the law of public opinion propagation on the three-party evolutionary game. The following is a numerical simulation using python software to analyze the influence of public opinion dissemination on the government, contractors, and the public's tripartite stabilization strategy.

\section{Numerical Simulation Analysis}

In the process of network public opinion information dissemination, the time for public opinion information dissemination is relatively short. In this paper, the input and output of network users are not considered. That is, the network structure and the total number of network users remain unchanged during the process of public opinion dissemination. Define the total number of network nodes as $N=20000, m=2,<k>=10$ [26]. According to the defined parameters, the python copy network software package network is used to generate the BA scale-free network model proposed by Albert [27]. It is assumed that the public who chooses public opinion supervision is the initial network public opinion, and the rest of the nodes are ignorant, i.e., $S 0=19999, E 0=0, I 0=1, R 0=0, C 1=4, C 2=1, C 3=1$, $P b=2, P 1=5, P 2=2, \alpha=0.3, x 0=0.5, y 0=0.5, z 0=0.5$.

4.1. The Impact of Public Losses on Public Strategy Choices. Residents affected by the project, $A \neq 0$. Unprofitable social citizen, $\quad A=0 ; \quad k=1, \rho_{1}=0.1, \rho_{2}=0.2, \beta_{1}=0.1, \beta_{2}=$ $0.2, \varepsilon_{1}=0.5, \varepsilon_{2}=0.4, \gamma_{1}=0.5, \gamma_{2}=0.4, \tau_{1}=0.02, \tau_{2}=0.05$, $m_{1}=f_{1}=g_{1}=0.0003, m_{2}=f_{2}=g_{2}=0.00008, a=0.7$.

The public losses are, respectively, taken as $0,0.2,0.5,1$, and 3 , and the influence of public losses on the evolutionary game strategy of the public is analyzed. The results are shown in Figure 2.

It can be seen from the simulation diagram that the probability of the public choosing public opinion supervision is positively correlated with public loss. With the increase of public losses, the public tends to choose public opinion supervision.

This shows that even when the cost of public opinion supervision is relatively low, the benefits of some public opinion supervision are still lower than the cost. But for the residents affected by the project, when their losses are relatively large, they will choose public opinion supervision. When citizens in an unprofitable society tend to choose public opinion supervision, the affected residents must also tend to choose public opinion supervision. Taking the citizens of an unprofitable society as the representative, analyze the influence of various parameters on the public evolution strategy.

4.2. The Influence of the Initial Communicator's Node Degree on the Choice of Three-Party Strategy

$$
\begin{aligned}
& \rho_{1}=0.1, \rho_{2}=0.2, \beta_{1}=0.1, \beta_{2}=0.2, \varepsilon_{1}=0.5, \varepsilon_{2}=0.4, \gamma_{1}=0.5, \gamma_{2}=0.4, \tau_{1}=0.02, \\
& \tau_{2}=0.05, m_{1}=f_{1}=g_{1}=0.0003, m_{2}=f_{2}=g_{2}=0.00008, a=0.7 .
\end{aligned}
$$




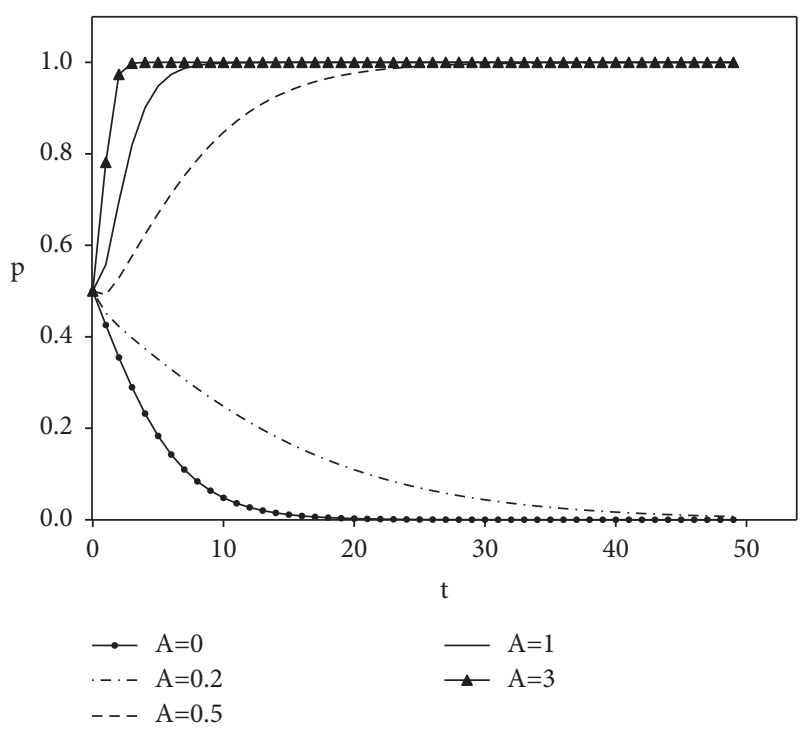

FIGURE 2: The impact of public losses on public evolution strategies.

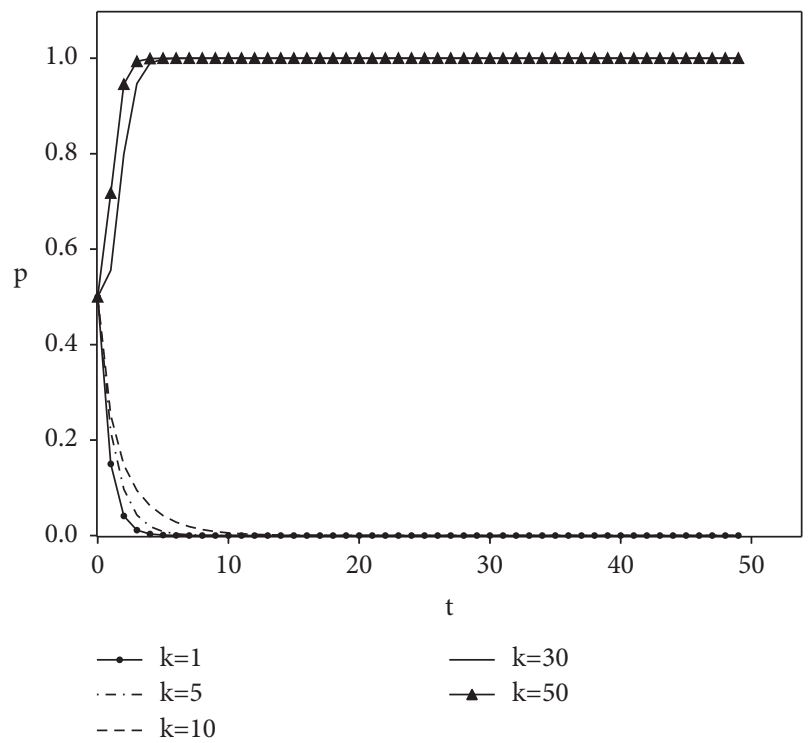

FIGURE 3: The impact of the initial spreading node degree on the government's evolutionary strategy.

The initial communicator node degrees are 1, 5, 10, 30, and 50. The result is shown in Figures 3-5. Figure 3 shows the changes in government evolution strategies under different values. The smaller the initial communicator node degree is, the faster the government chooses not to supervise actively. Figure 4 also shows that, with increasing, contractors tend to choose normal quality behaviors. Figure 5 shows that the public's node degree is relatively small, the speed and scope of public opinion dissemination are very low, and the public's income is low. Therefore, the public chooses not to oversee public opinion. But it can be found that this situation occurs only when the node degree is extremely small. This is because the cost for the public to monitor the quality behavior of contractors through new online media is very low, leading to the fact that the benefits

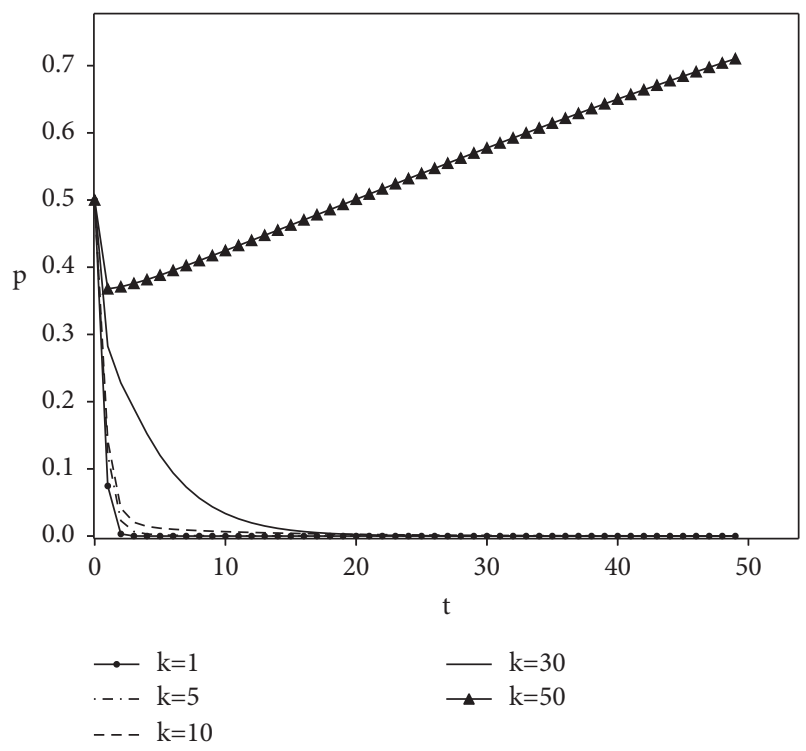

Figure 4: The influence of initial propagation node degree on contractor's evolution strategy.

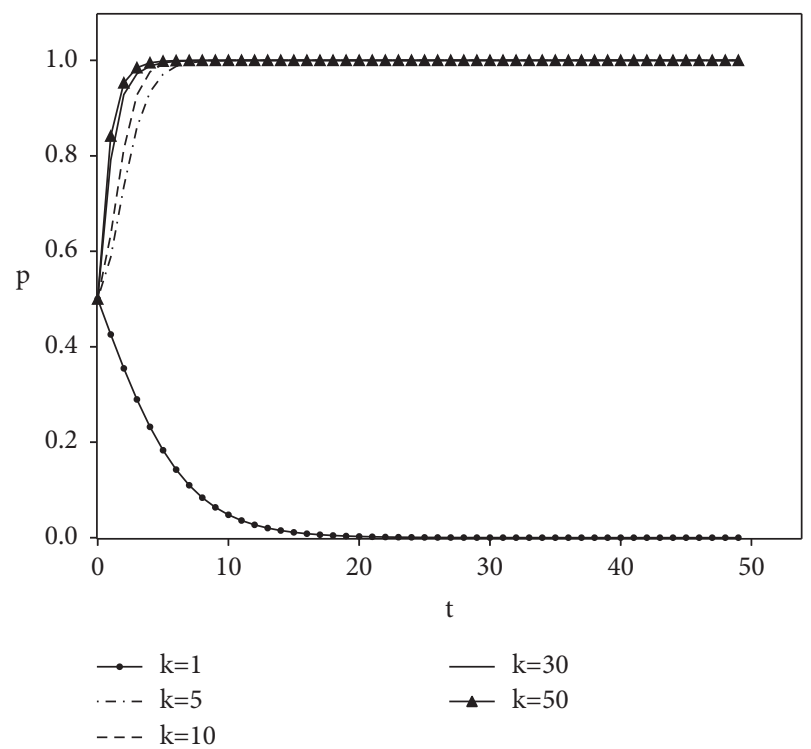

Figure 5: The influence of the initial dissemination node degree on the public evolution strategy.

of the public's choice of public opinion supervision outweigh the cost. This conclusion shows that the public with low nodes will still choose public opinion supervision due to the low cost, but it may not be able to restrain the government and contractors. Only when the number of public friends with a relatively high node degree is large, and their influence is high can the government choose active supervision and contractors to choose normal quality behaviors.

4.3. The Impact of the Conversion Probability between Nodes on the Choice of Three-Party Strategy. Setting parameters: $k=20, \quad m 1=f 1=g 1=0.0003, \quad m 2=f 2=0.00008, \quad a=0.7$, $\rho 1=0.1,0.3,0.5,0.7,0.9$, and $\rho 2=0.2,0.4,0.6,0.8,1.0$. 


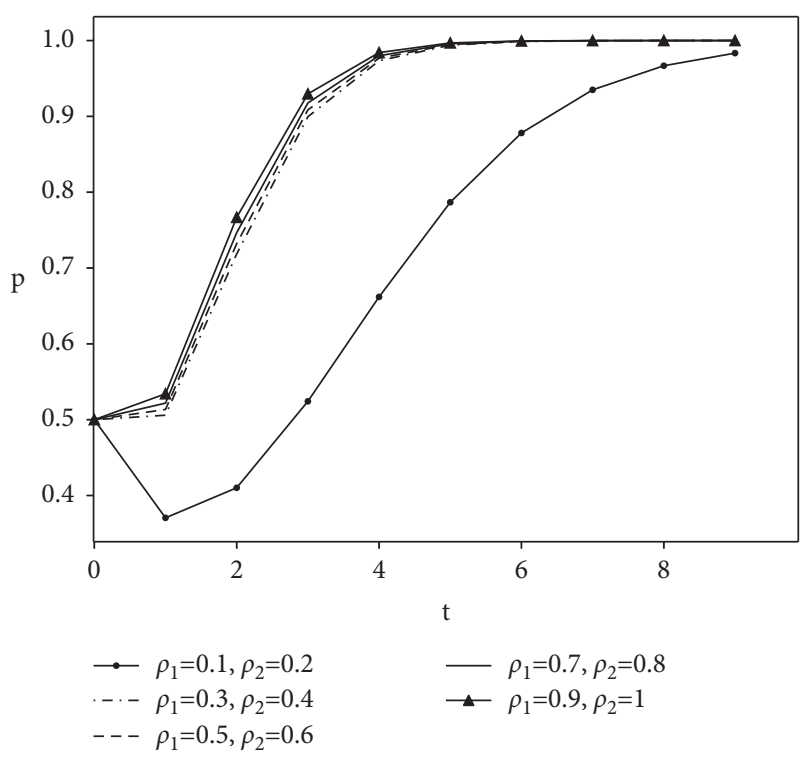

Figure 6: The impact of the probability of the ignorant transforming.

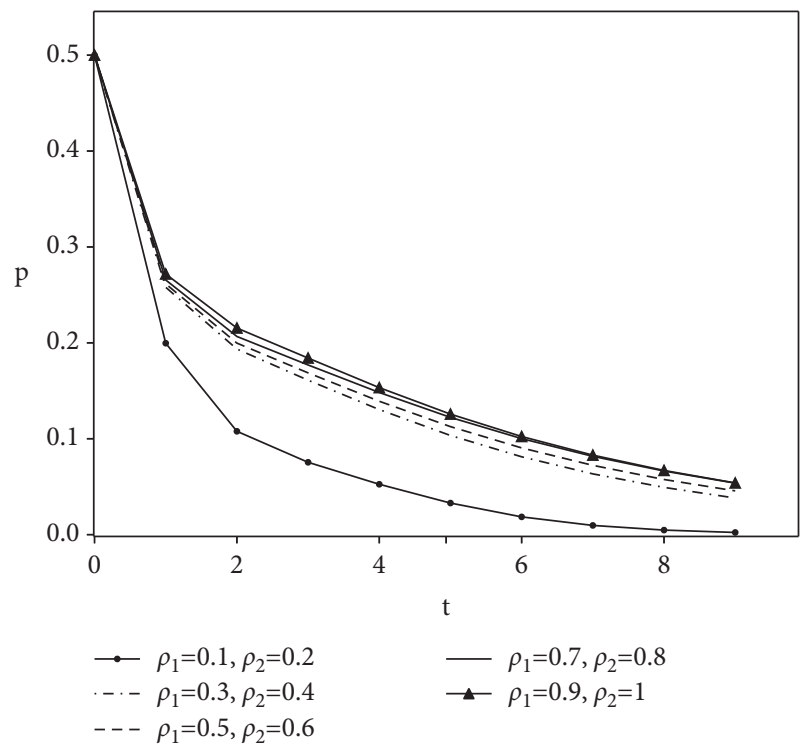

Figure 7: The impact of the probability of the ignorant person turning into a latent person on the contractor's evolutionary strategy.

The simulation result is shown in Figures 6-8. It can be seen from Figures 6-8 that changing the probability of transforming an ignorant into a latent does not change the trend of the government, contractors, and the public in the choice of strategy. It can be seen that the increase in the probability of the ignorant transforming into the latent has an impact on the three-party strategy choice of the game player. The government tends to choose active supervision faster. Contractors tend to choose quality deceptions at a slower rate. The probability that the public chooses public opinion supervision to stabilize at 1 is faster. This shows that the change in the conversion probability of ignorant people

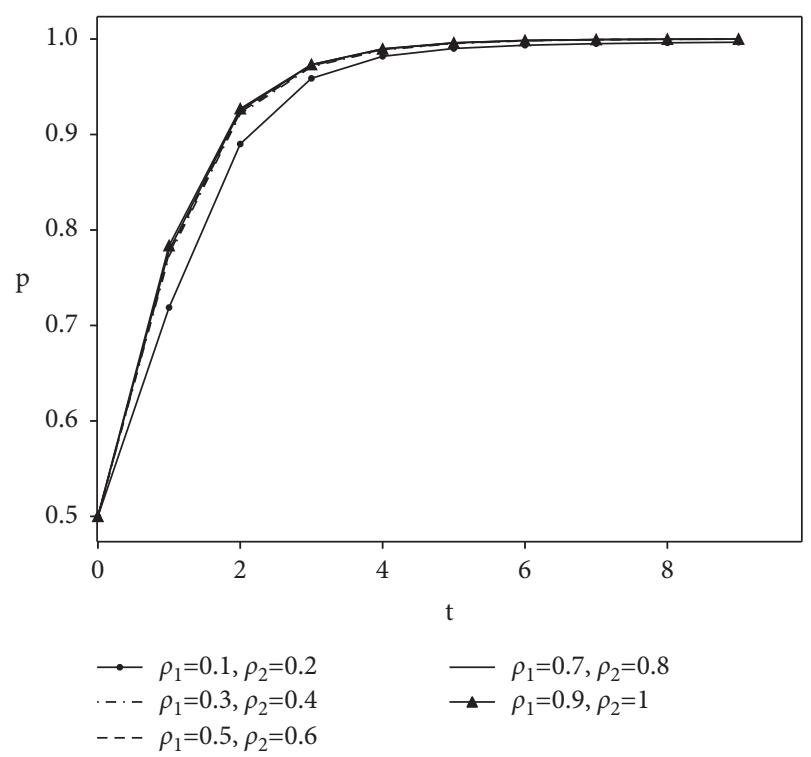

FIgURE 8: The impact of the probability of the ignorant person turning into a latent person on the public evolution strategy.

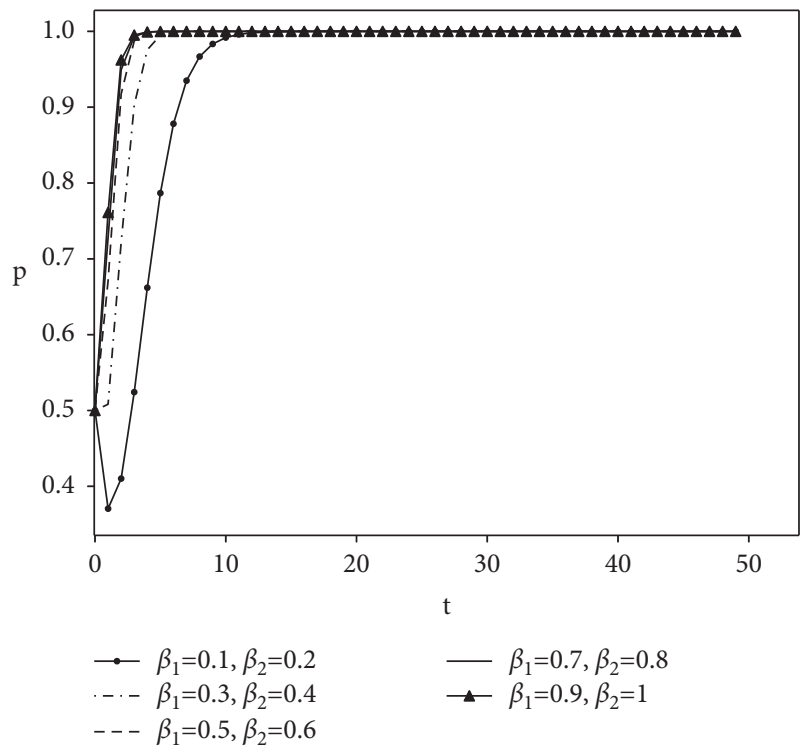

FIGURE 9: The impact of the probability of a latent person turning into a communicator on the government's evolutionary strategy.

to latent people directly affects the spread of public opinion and changes the income of the government and contractors.

It can be seen from Figures 5 and 8 that the cost of public opinion supervision is low. Except for the public with a very low degree of nodes, the public will choose not to conduct public opinion supervision. Others tend to choose public opinion supervision. The impact of the conversion probability between nodes on the public strategy only speeds up the public's tendency to choose public opinion supervision. Therefore, the influence on the public is not considered in the influence of the conversion probability between nodes on the three-party evolution strategy below. 


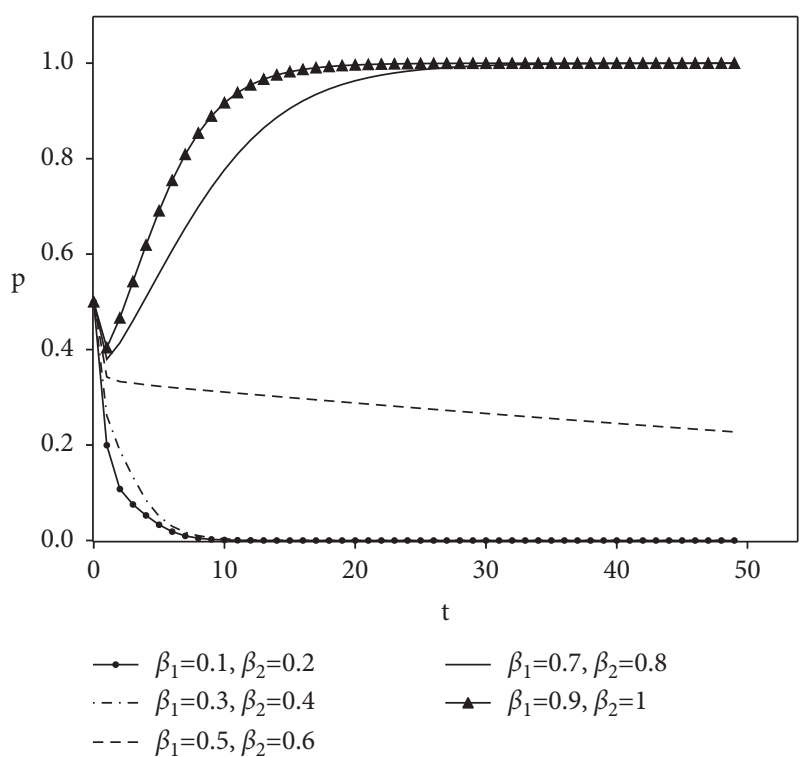

Figure 10: The impact of the probability of the conversion of a latent person into a communicator on the contractor's evolutionary strategy.

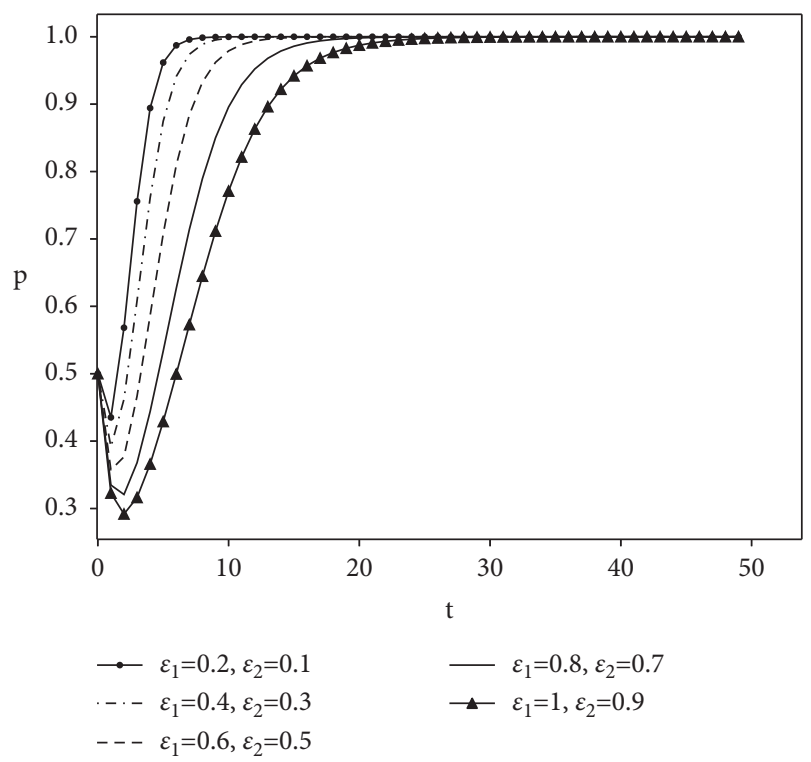

FIGURE 11: The impact of direct immunization rate on government evolution strategy.

Setting parameters: $\rho 1=0.1, \rho 2=0.2, \varepsilon 1=0.5, \varepsilon 2=0.4$, $\gamma 1=0.5, \gamma 2=0.4, \tau 1=0.02, \tau 2=0.05, \beta 1=0.1,0.3,0.5,0.7$, 0.9 , and $\beta 2=0.2,0.4,0.6,0.8,1.0$.

Carry on the numerical simulation; the result is shown as in Figures 9 and 10. It can be seen from Figure 9 that as the conversion probability of a latent person to communicator increases, the rate at which the government chooses active supervision to stabilize at 1 speeds up. It can be seen from

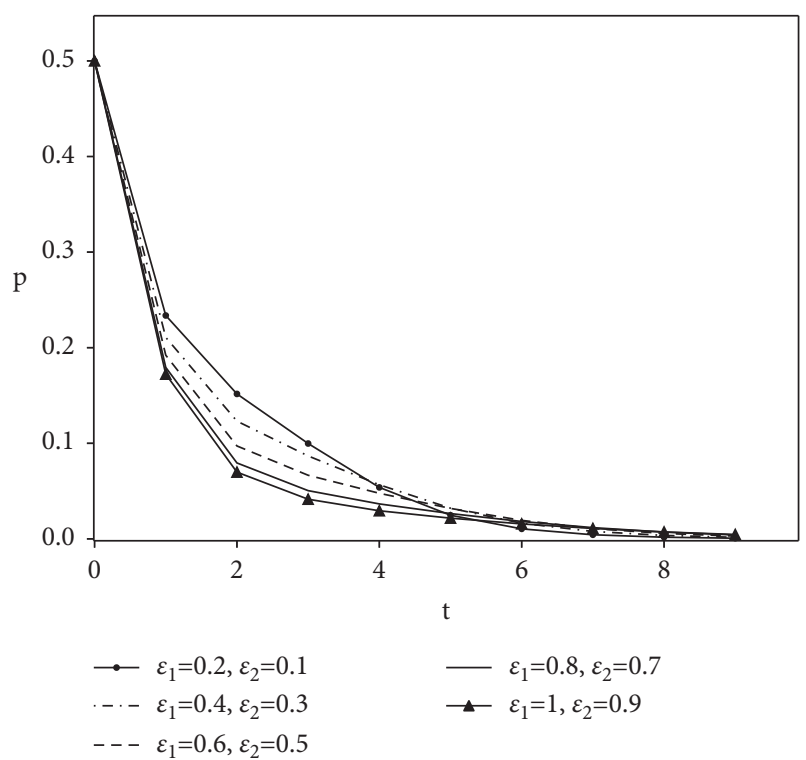

FIgURE 12: The impact of direct immunity rate on contractor's evolutionary strategy.

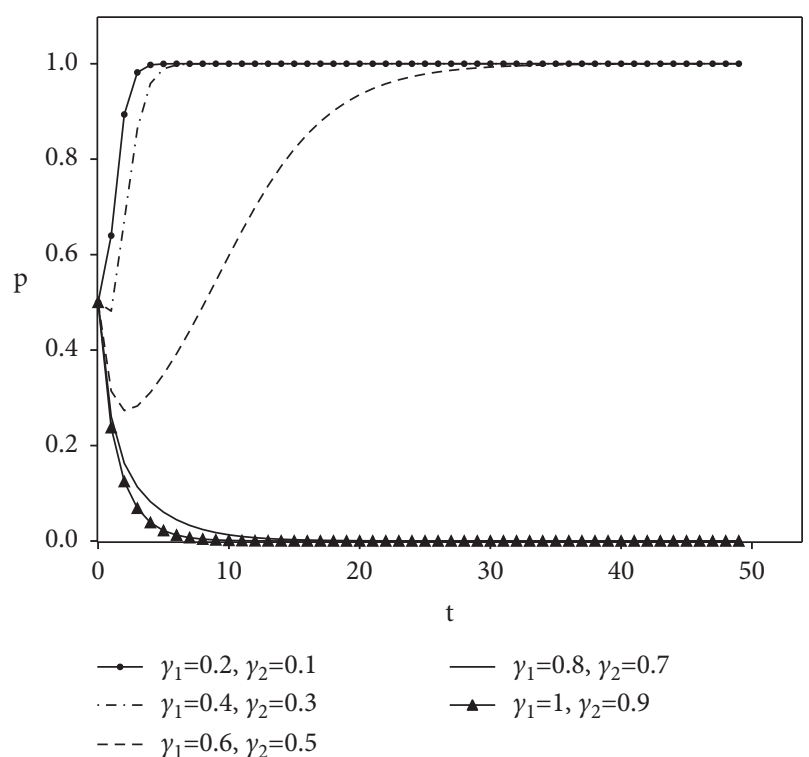

FIGURE 13: The influence of the propagator's self-healing probability on the government's evolutionary strategy.

Figure 10 that the contractor's evolutionary strategy tends to choose normal quality behavior.

Setting parameters: $\rho 1=0.1, \rho 2=0.2, \beta 1=0.1, \beta 2=0.2$, $\gamma 1=0.5, \gamma 2=0.4, \tau 1=0.02, \tau 2=0.05, \varepsilon 2=0.1,0.3,0.5,0.7$, 0.9 , and $\varepsilon 1=0.2,0.4,0.6,0.8,1.0$.

The simulation result is shown in Figures 11 and 12. From Figure 11, it can be seen that as the direct immunization rate reduces, the probability at which the government chooses active supervision to stabilize at 1 speeds up. It can be seen from Figure 12 that the contractor's evolutionary 


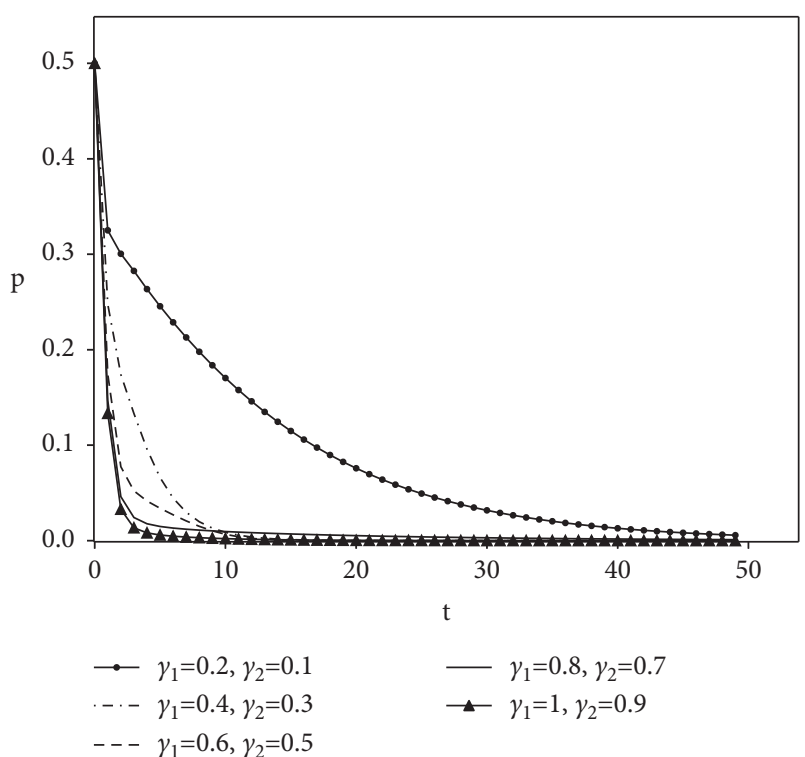

FIGURE 14: The influence of the propagator's self-healing probability on the contractor's evolutionary strategy.

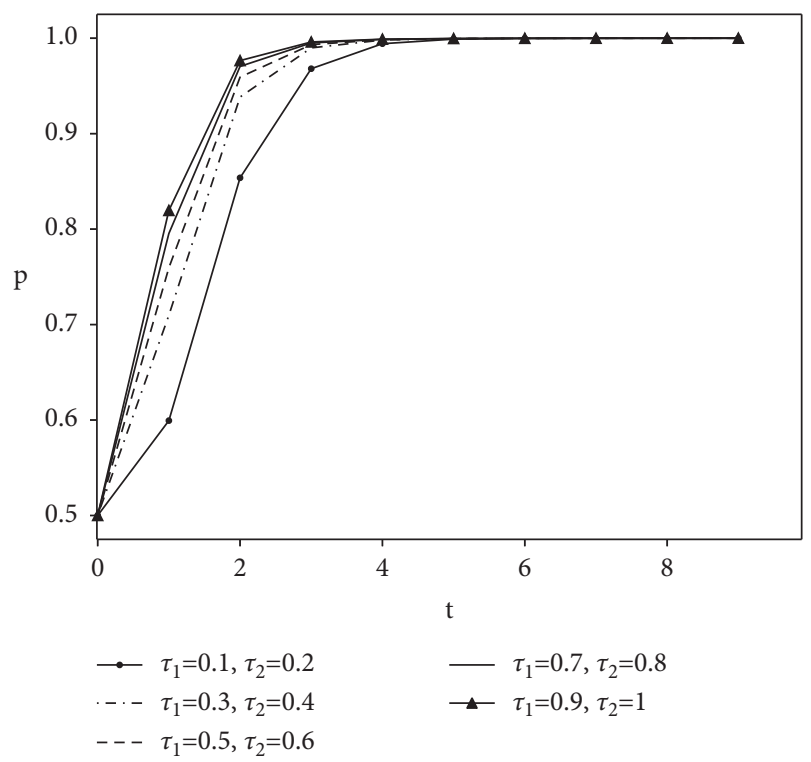

Figure 15: The impact of topic derivation rate on government evolution strategy.

strategy tends to increase the speed of choosing quality deception.

Setting parameters: $\rho 1=0.1, \rho 2=0.2, \beta 1=0.1, \beta 2=0.2$, $\varepsilon 1=0.5, \varepsilon 2=0.4, \tau 1=0.02, \tau 2=0.05, \gamma 2=0.1,0.3,0.5,0.7$, 0.9 , and $\gamma 1=0.2,0.4,0.6,0.8,1.0$.

The simulation result is shown in Figures 13 and 14. It can be seen from Figures 13 and 14 that the change in the probability of the communicator's self-healing has a greater impact on the government and contractors. Increasing the speed of the spread of online public opinion, contractors tend to choose quality deception slower.

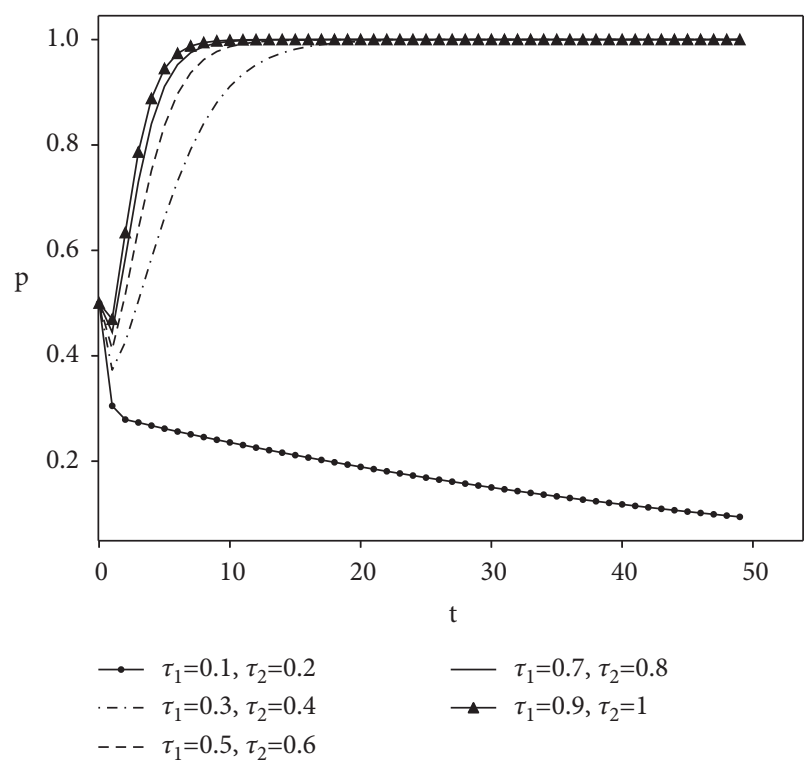

FIgURE 16: The impact of topic derivation rate on contractor's evolution strategy.

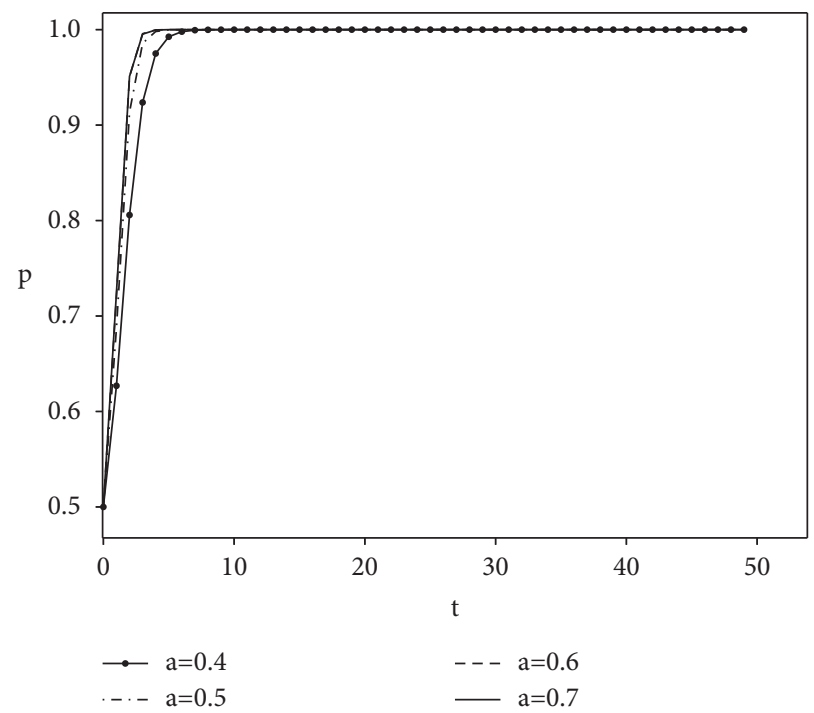

FIGURE 17: The impact of authenticity on government evolution strategies.

Setting parameters: $\rho 1=0.1, \rho 2=0.2, \beta 1=0.1, \beta 2=0.2$, $\varepsilon 1=0.5, \varepsilon 2=0.4, \gamma 1=0.5, \gamma 2=0.4, \tau 1=0.1,0.3,0.5,0.7,0.9$, and $\tau 2=0.2,0.4,0.6,0.8,1.0$.

The numerical simulation results are shown in Figures 15 and 16. It can be seen from Figures 15 and 16 that the contractor's probability of choosing normal quality behavior is stable at 1 . The main reason is the increase in topic derivation rate, which leads to an increase in the cost of the government choosing not to actively supervise.

Cao et al. [11] research shows that with faster spread of new media reports or greater scope of influence, the government will also urge the government to perform its duties seriously. Cao Yuxi and $\mathrm{Wu}$ [14] found that the greater the 


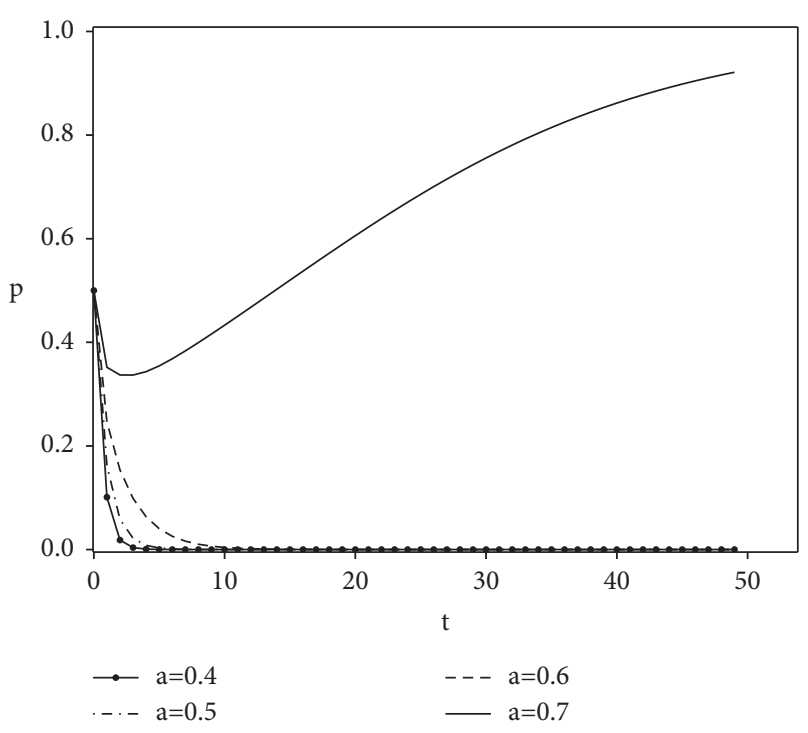

FIGURE 18: The impact of authenticity on the contractor's evolutionary strategy.

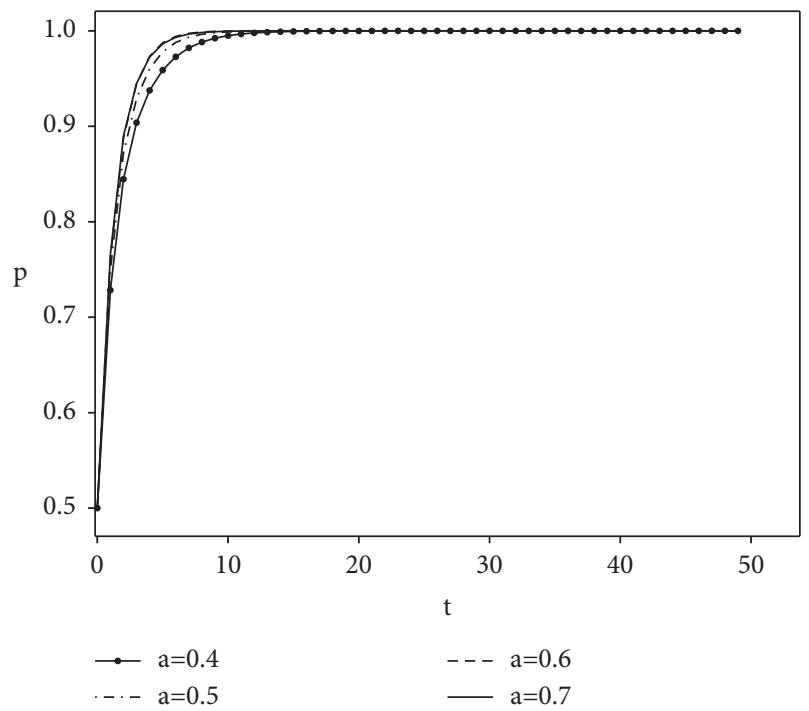

FIgURE 19: The impact of authenticity on public evolution strategies.

influence of online public opinion is, the faster the three parties in the game will reach the ideal state. The probability of government active supervision is positively correlated with the probability of the ignorant transforming into a latent person and negatively correlated with the direct immunity rate and the probability of the communicator's self-healing. This is because increasing the probability of the ignorant transforming into a latent, the probability of transforming a latent into a communicator, and the topic derivation rate can expand the influence of online public opinion. The change of the conversion probability between nodes affects the influence of the network public opinion and then affects the strategy choice of the three players in the game. As the probability of the communicator's self-healing

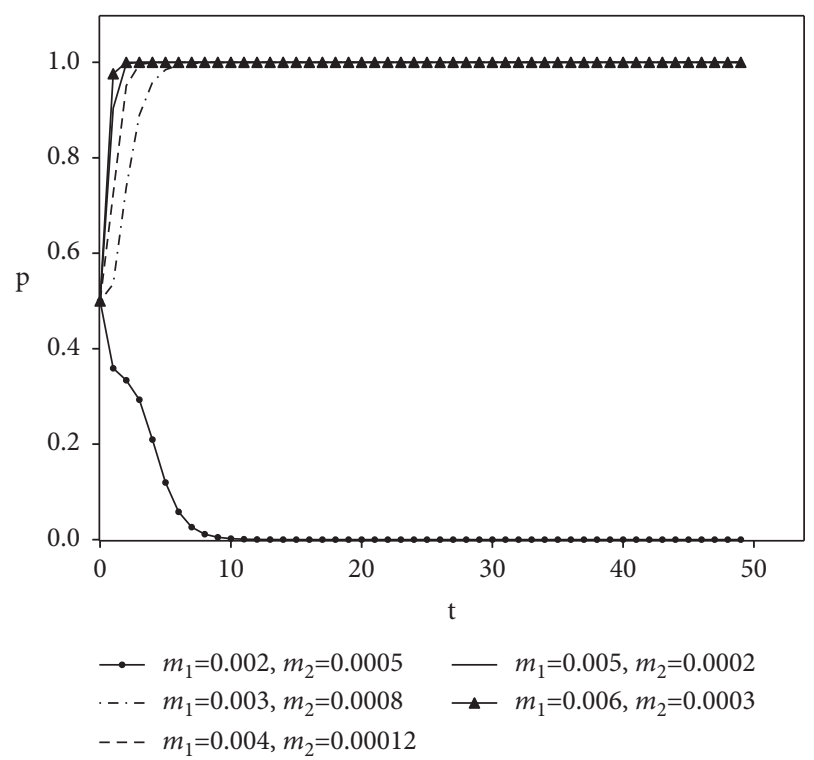

FIGURE 20: The impact of government credibility on the evolutionary game of government.

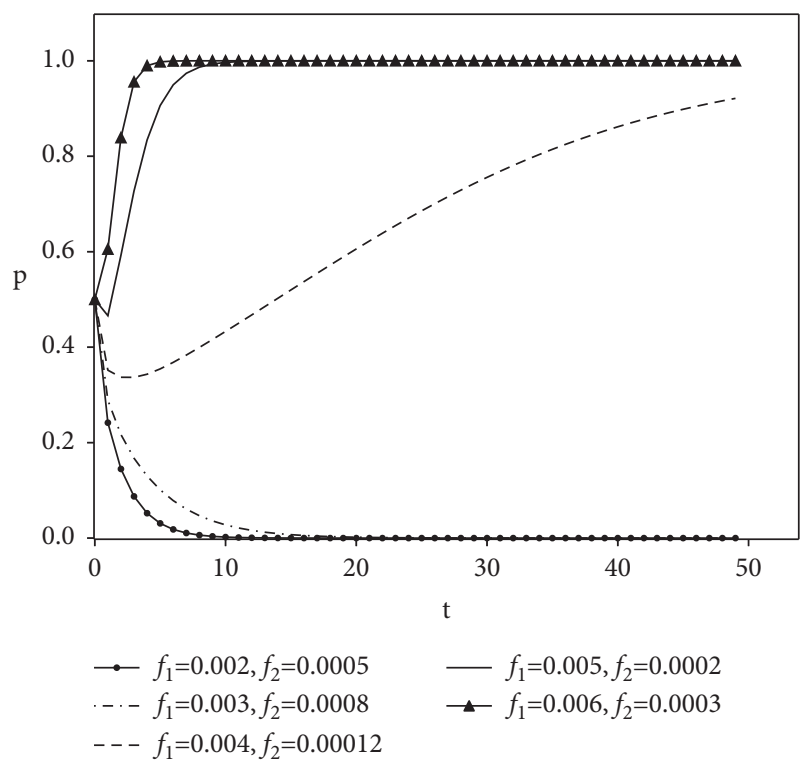

Figure 21: The impact of contractor unit opportunity cost on contractor's evolution strategy.

decreases, the government has evolved from choosing not to regulate to actively choose an active regulatory strategy. The conversion probability of lurkers to communicators and topic derivation rate significantly impact the contractor's strategic choice.

Therefore, if the higher-level government wants to improve the effectiveness of public opinion overseeing the quality of behavior, this can be done by increasing the probability of a latent person transforming into a communicator, increasing the topic derivation rate, and reducing the probability of a communicator's self-healing. 
4.4. The Impact of the Authenticity of Public Opinion Supervision on the Choice of Tripartite Strategies. Setting parameters:

$k=30, \rho_{1}=0.1, \rho_{2}=0.2, \beta_{1}=0.1, \beta_{2}=0.2, \varepsilon_{1}=0.5, \varepsilon_{2}=$ $0.4, \gamma_{1}=0.5, \gamma_{2}=0.4, \tau_{1}=0.02, \tau_{2}=0.05, m_{1}=f_{1}$ $=0.0004, \quad g_{1}=0.0003, m_{2}=f_{2}=0.00012, g_{2}=0.00008$, and $a=0.4,0.5,0.6,0.7$.

Carry on the numerical simulation analysis, and the result is shown as in Figures 17-19. It is found that the authenticity of public opinion supervision is positively correlated with the probability that the government chooses active supervision. This is because the authenticity of public opinion supervision has increased, and the benefits of the public's choice of public opinion supervision outweigh the cost.

4.5. The Influence of the Unit Change of Credibility and Unit Opportunity Cost on the Government and Contractor's Strategic Choice. Setting parameters:

$$
\begin{aligned}
& \tau_{2}=0.05, g_{1}=0.0003, g_{2}=0.00008, a=0.7 . k=30, \\
& \rho_{1}=0.1, \rho_{2}=0.2, \beta_{1}=0.1, \beta_{2}=0.2, \varepsilon_{1}=0.5, \varepsilon_{2}= \\
& 0.4, \gamma_{1}=0.5, \gamma_{2}=0.4, \tau_{1}=0.02, \quad f_{1}=0.0004 \\
& f_{2}=0.00012 . \\
& m_{1}=0.0002,0.0003,0.0004,0.0005,0.0006 . \\
& m_{2}=0.00005,0.00008,0.00012,0.0002,0.0003 .
\end{aligned}
$$

The numerical simulation result of setting parameters is shown in Figure 20. As the credibility of government units increases, the government tends to choose active supervision, and the greater the credibility of the unit is, the faster the government tends to choose active supervision. This is because when the credibility of government units is relatively high, the benefits of the government choosing to supervise actively are greater than choosing not to supervise actively.

(1) $m_{1}=0.0004, m_{2}=0.00012, \quad f_{1}=0.0002, \quad 0.0003$, $0.0004, \quad 0.0005, \quad 0.0006, f_{2}=0.00005, \quad 0.00008$, $0.00012,0.0002,0.0003$.

Carry on numerical simulation; the result is shown as in Figure 21. Figure 21 shows that the contractor's probability of choosing normal quality behavior is positively correlated with unit opportunity cost; that is, as the contractor's unit opportunity cost increases, the contractor's probability of choosing normal quality behavior stabilizes at 1 . Thus, with the increase of contractor unit opportunity cost, the cost of contractor choosing quality deception is higher. Therefore, to reduce cost, the contractor will choose normal quality behavior.

The above analysis shows that the higher-level government can take measures to increase the government's unit credibility or increase the contractor's unit opportunity cost and improve the effectiveness of public opinion supervision.

\section{Conclusion}

This article considers the positive effects of new media on the Internet, coupling the law of the spread of public opinion on the Internet and the evolutionary game model. Analyze the influence of the law of public opinion dissemination on the government, contractors, and the public's evolutionary game strategy, concluded as follows.

(1) In the process of public opinion supervision, ordinary people's online public opinion supervision is less effective in restricting the quality behavior of the government and contractors. The public network supervision with greater influence or authority is more effective in restraining the government and contractors. Therefore, the influential and authoritative public should increase their awareness of public opinion supervision. Actively supervise the quality behavior of contractors. The high authenticity of public opinion supervision can effectively restrain the quality behavior of contractors.

(2) Numerical simulation shows that the conversion probability between nodes is a key factor affecting the influence of network public opinion. The higherlevel government reports on the public opinion of the verification facts. Announce it online and use more channels for dissemination. You can also train web commentators to post or reprint posts that reflect the truth on the Internet. Thus, you can expand the scope of online public opinion and increase the interest of cultivating opinion leaders.

(3) The higher-level government should publicly report the quality behavior of the government and contractors. In addition, the quality behavior of contractors shall be used as an essential indicator of bidding and enterprise evaluation.

The model constructed in this paper deeply explores the influence of the law of public opinion dissemination on the strategy choice of the game party in the supervision of public social opinion on engineering quality, conducive to improving the effectiveness of online public opinion monitoring quality behavior. But this article considers the benefits of the initial public's online supervision. In further research, the supervision of the public at different stages of online public opinion can be analyzed. It is also possible to consider the influence of factors such as time lag and social strengthening mechanisms on the quality of online public opinion supervision. When a quality problem occurs in a project, web crawlers and other technologies are used to extract network data to verify the effectiveness of the theoretical model.

\section{Data Availability}

The labeled dataset used to support the findings of this study are available from the corresponding author upon request.

\section{Conflicts of Interest}

The authors declare that they have no conflicts of interest.

\section{Acknowledgments}

This paper was supported by the National Natural Science Foundation of China (51709116 and 42007158), Henan 
Province Discipline Innovation and Intelligence Introduction Base Project "Smart Water Conservancy" (GXJD004), and the Henan Key Laboratory of Water Resources Conservation and Intensive Utilization in the Yellow River Basin, Zhengzhou, (China).

\section{References}

[1] D. Y. Jiang, K. Ren, and X. C. Qing, "Analysis of construction safety management and the suggestions," Engineering Construction and Design, no. 5, pp. 212-214, 2020.

[2] The State Council of the people's Republic of China, Guidance of the CPC Central Committee and the State Council on Carrying Out Quality Improvement Actions [EB/OL], http://www.gov.cn/zhengce/2017-09/12/content_ 5224580. htm, 2017.

[3] X. Q. Wang and X. Y. Sun, "Evolutionary game analysis on supervision governance of chemical enterprises based on public participation behavior," China Science and technology of work safety, vol. 14, no. 3, pp. 180-186, 2018.

[4] S. H. Sun and L. L. Zhu, "Game Analysis of government food safety supervision under social evaluation mechanism," Consumer economy, vol. 33, no. 6, pp. 74-79, 2017.

[5] Y. Chen, J. Zhang, P. R. Tadikamalla, and X. Gao, "The relationship among government, enterprise, and public in environmental governance from the perspective of multi-player evolutionary game," International Journal of Environmental Research and Public Health, vol. 16, no. 18, p. 3351, 2019.

[6] J. W. Chang, L. W. Zhao, and J. G. Du, "Supervision evolutionary game analysis and stability control of corporate environmental behavior-based on system dynamics," Systems Engineering, vol. 35, no. 10, pp. 79-87, 2017.

[7] R. Lu, Z. Wang, and J. Ding, "Evolutionary game analysis of environmental protection PPP project's operation supervision with public participation," Science and Technology Management Research, vol. 39, no. 6, pp. 184-191, 2019.

[8] X. Wu, J. Liu, and Y. Pang, "A study on the incentive mechanism of public participation behavior in the large-scale public projects investment decision based on system evolutionary game model," Journal of Engineering Management, vol. 34, no. 6, pp. 83-88, 2020.

[9] S. He, G. Liang, and J. Meng, "Multi-subjects benefit game and behavior evolution mechanism of major engineering based on prospect theory," Science and Technology Management Research, vol. 40, no. 5, pp. 207-214, 2020.

[10] Y. Peng, J. Li, H. Xia, S. Qi, and J. Li, "The effects of food safety issues released by we media on consumers' awareness and purchasing behavior: a case study in China," Food Policy, vol. 51, no. 1, pp. 44-52, 2015.

[11] Y. Cao, Z. Yu, and G. Wan, "Research on the evolutionary game of government and enterprises in food adulteration in the new media environment," Chinese Management Science, vol. 25, no. 6, pp. 179-187, 2017.

[12] S. Sun and L. L. Zhu, "Simulation analysis of tripartite evolution of public participation in food quality supervision under the new media environment," Management Review, vol. 33, no. 3, pp. 315-326, 2021.

[13] W. Fei and Y. Pan, "The evolutionary game of food safety between self-media, regulatory agencies and enterprises," Journal of South China Agricultural University, vol. 19, no. 6, pp. 84-100, 2020.

[14] X. Cao and W. Wu, "The evolutionary game research on the tripartite cooperative supervision of social organizations in the "Internet+" Environment," Journal of Central China
Normal University (Natural Science Edition), vol. 55, no. 02, pp. 317-328, 2021.

[15] W. Goffman and V. A. Newill, "Generalization of epidemic theory: an application to the transmission of ideas; an application to the transmission of ideas," Nature, vol. 204, no. 4955, pp. 225-228, 1964.

[16] R. Pastor-Satorras and A. Vespignani, "Epidemic spreading in scale-free networks," Physical Review Letters, vol. 86, no. 14, pp. 3200-3203, 2001.

[17] J. Stehlé, N. Voirin, and A. Barrat, "Simulation of an SEIR infectious disease model on the dynamic contact network of conference attendees," BMC Medicine, vol. 9, no. 1, p. 87, 2011.

[18] X. Ding, "Research on micro blog public opinion topic communication model based on SCIR," Computer Engineering and Applications, vol. 51, no. 8, pp. 20-26+78, 2015.

[19] Y. Zhang, Y. Su, L. Weigang, and H. Liu, "Rumor and authoritative information propagation model considering super spreading in complex social networks," Physica A: Statistical Mechanics and its Applications, vol. 506, pp. 395-411, 2018.

[20] S. Yu, Z. Yu, H. Jiang, and J. Li, "Dynamical study and eventtriggered impulsive control of rumor propagation model on heterogeneous social network incorporating delay," Chaos, Solitons \& Fractals, vol. 145, p. 110806, 2021.

[21] W. Ma, O. Zhao, and F. Han, "Research on the application of improved odel in the dissemination of reading promotion information in university libraries," Library and Information Servic, vol. 64, no. 20, pp. 74-80, 2020.

[22] J. Yi, P. Y. Liu, and X. B. Tang, "Improved SIR advertising spreading model and its effectiveness in social network," Procedia Computer Science, vol. 129, pp. 215-218, 2018.

[23] F. Chen, T. Chen, and X. Zheng, "Research on the dissemination behavior of internet public opinion on a new SEIRS model," Information and Documentation Services, no. 4, pp. 62-67, 2014.

[24] K. Heret, Evolutionary Game Theory (Second Edition)-Problem Oriented and Strategic Interactive Model, Renmin University of China Press, Beijing, China, 2016.

[25] D. Friedman, "Evolutionary games in economics," Econometrica, vol. 59, no. 3, pp. 637-666, 1991.

[26] Z. Zhu and Y. Liu, "Simulation research on rumor spreading in online social networks-based on a scale-free network environment with variable clustering coefficients," Complex Systems and Complexity Science, vol. 13, no. 2, pp. 74-82, 2016.

[27] A. L. Barabási and R. Albert, "Emergence of scaling in random networks,” Science, vol. 286, no. 5439, pp. 509-512, 1999. 